\title{
Effects of Age on the Disruption of Cognitive Performance by Exposure to Space Radiation
}

\author{
Bernard M. Rabin1, Barbara Shukitt-Hale², Kirsty L. Carrihill-Knoll1 \\ ${ }^{1}$ Department of Psychology, University of Maryland Baltimore County, Baltimore, MD, USA \\ ${ }^{2}$ Human Nutrition Research Center on Aging, USDA-ARS, Tufts University, Boston, MA, USA \\ Email: rabin@umbc.edu
}

Received 17 May 2014; revised 24 June 2014; accepted 10 July 2014

Copyright (C) 2014 by authors and Scientific Research Publishing Inc.

This work is licensed under the Creative Commons Attribution International License (CC BY). http://creativecommons.org/licenses/by/4.0/

c) (i) Open Access

\begin{abstract}
Exposure to low doses of heavy particles and protons, which will be encountered during long-term exploratory class missions to other planets, can cause deficits in cognitive performance. These deficits are similar to those observed in aged animals. The long-term effects of such exposures and their relationship to the short-term effects and to aging remain to be established. Two-month old rats were exposed to a variety of heavy particles and protons. Recognition memory was tested at two time points following irradiation. The results showed that exposure to doses of radiation that did not disrupt cognitive performance in the younger animals, disrupted performance when the subjects were re-tested at an older age. These results indicate that there is an interaction between the age of the organism and the effects of exposure to space radiation on cognitive performance, such that exposure to doses of heavy particles or protons that may not produce an initial effect on cognitive performance may produce an effect as the organism ages. Because of the interaction between exposure to the types of radiation encountered in space and age, it is possible that participating in exploratory class missions may have consequences for the quality of life after the conclusion of the mission.
\end{abstract}

\section{Keywords}

Cosmic Rays, Memory, Aging

\section{Introduction}

On exploratory class missions to Mars astronauts will be exposed to types of radiation (cosmic rays) not expe- 
rienced in low earth orbit [1]-[3]. Cosmic rays are composed of protons and particles of high energy and charge (HZE particles). Exposing young rats ( $\approx 2$ months of age) to HZE particles can produce "accelerated aging” such that irradiated rats show neural and cognitive deficits that are characteristic of old animals [4]-[6]. In the shortterm (1 - 4 months post-irradiation) there is a deficit in the performance of cognitive tasks, including operant responding [7], fear conditioning [8] and spatial learning and memory [9] [10]. However, the long-term consequences of exposure to HZE particles and the relationship to the short-term effects remain to be fully determined. Research to-date using operant responding on an ascending fixed-ratio schedule (which measures the responsiveness of the organism to changes in environmental stimuli and their motivation to respond to changes in reinforcement schedules) and a single HZE particle $\left({ }^{56} \mathrm{Fe}\right)$ has shown that cognitive performance following exposure to HZE particles is a function of both the time since exposure [11] as well as age of irradiation [12]. These results suggest that exposure to doses of HZE particles that are not high enough to affect cognitive performance at the time of exposure, may affect performance at some later time.

The present experiment was designed to evaluate the age-related changes in the sensitivity to exposure to the range of particles that make up the spectrum of cosmic rays to which astronauts will be exposed and the changes in sensitivity as a function of the increased age of the subject. The level of performance was measured by determining the threshold dose (the lowest dose of a particle) which produced a change in performance compared to non-irradiated control animals at two time intervals. As such, it should be possible to determine whether or not there is no change in performance, recovery of function or continued deterioration of performance as a function of time following exposure. Because exposure to HZE particles and protons during a long-duration exploratory class mission may have implications for the quality of life after the completion of the mission, it is important to determine how the age of the organism interacts with exposure to cosmic rays.

\section{Methods}

\subsection{Subjects}

The subjects were male Sprague-Dawley rats weighing 200 - $225 \mathrm{~g}$ at the time of irradiation. These rats were approximately 2 months of age at the time of irradiation. Prior to irradiation, the rats were maintained in an AAALAC-accredited facility at Brookhaven National Laboratory (BNL). After irradiation the rats were shipped to University of Maryland Baltimore County (UMBC) for behavioral testing. The facility at UMBC is monitored by the Comparative Medicine and Veterinary Resources division of the University of Maryland, Baltimore School of Medicine. All procedures were approved by the IACUCs of both BNL and UMBC. At both facilities the rats were maintained on a 12:12 hour light:dark cycle with food and water continuously available.

\subsection{Radiation}

The rats were radiated at the NASA Space Radiation Laboratory (NSRL) at BNL. Dosimetry was provided by the staff of the NSRL using parallel plate ionization chambers. Large area ion chambers were used to measure and trigger the cut-off of the beam once the requested dose had been delivered. These ion chambers were calibrated by simultaneously exposing a NIST-traceable thimble ion chamber to the beam after the beam energy was selected and beam shape tuned. Tungsten bricks four inches thick were used to collimate the beam to allow for exposures to the heads of the rats only.

Space radiation, heavy particles and protons, is characterized by the energy of the particle and by the Linear Energy Transfer (LET) of the particle, which is a measure of the energy deposited in tissue and, consequently, the amount of tissue damage. In general, the higher the LET of the particle, the greater the amount of tissue damage. The particles, energies and doses to which the rats were exposed are summarized in Table 1 . The initial sample size was ten rats/dose. For radiation, unanesthetized rats were restrained in well-ventilated plastic tubes. The nominal dose rates ( 5 - $100 \mathrm{cGy} / \mathrm{min}$ ) were adjusted so that the total irradiation time did not exceed 3 - 4 min; as such the animals given the higher total doses were also subjected to slightly higher dose rates.

\subsection{Behavior}

The novel object recognition task is a measure of recognition memory. This procedure has been described in detail previously [13]. Subjects are tested in an open field $(93 \mathrm{~cm} \times 93 \mathrm{~cm})$. The stimulus objects vary in shape and color. On the conditioning day two identical (familiar) stimulus objects are placed in symmetrical locations in 
Table 1. HZE particles and energies.

\begin{tabular}{|c|c|c|c|c|c|}
\hline \multirow{2}{*}{ Particle } & \multirow{2}{*}{$\begin{array}{c}\text { Energy } \\
(\mathrm{MeV} / \mathrm{n})\end{array}$} & \multirow{2}{*}{$\begin{array}{c}\text { LET } \\
(\mathrm{keV} / \mu \mathrm{m})\end{array}$} & \multirow{2}{*}{$\begin{array}{l}\text { Dose Range } \\
\text { (cGy) }\end{array}$} & \multicolumn{2}{|c|}{ Months Post-Irradiation } \\
\hline & & & & Test 1 & Test 2 \\
\hline${ }^{16} \mathrm{O}$ & 600 & 16 & $0.1-25.0$ & $2(70)^{*}$ & $10(64)$ \\
\hline${ }^{16} \mathrm{O}$ & 1000 & 14 & $5.0-200.0$ & $4(60)$ & $12(52)$ \\
\hline${ }^{12} \mathrm{C}$ & 290 & 13 & $5.0-150.0$ & $1(110)$ & $11(98)$ \\
\hline${ }^{28} \mathrm{Si}$ & 380 & 50 & $0.5-100.0$ & $4(64)$ & $10(49)$ \\
\hline${ }^{28} \mathrm{Si}$ & 600 & 44 & $10.0-200.0$ & $5(88)$ & $9(79)$ \\
\hline${ }^{28} \mathrm{Si}$ & 1000 & 41 & $25.0-200.0$ & $4(88)$ & $13(73)$ \\
\hline${ }^{48} \mathrm{Ti}$ & 1100 & 106 & $25.0-100.0$ & $7(67)$ & $17(45)$ \\
\hline${ }^{56} \mathrm{Fe}$ & 600 & 181 & $10.0-150.0$ & $3(52)$ & $12(55)$ \\
\hline Proton & 1000 & 0.22 & $35.0-200.0$ & $4(109)$ & $13(79)$ \\
\hline
\end{tabular}

*) Number of subjects tested. The initial sample size was 10 rats/dose.

the open field. The rat is allowed to explore the stimuli until it accumulates 25 - 30 sec total object exploration (i.e., exploration of either object) or until 15 min have passed. On the test day, $24 \mathrm{hr}$ later, the rat is placed back in the field with one familiar and one novel object and allowed to explore both stimuli until it has accumulated 25 - 30 sec of object exploration on either object or until 15 min have passed. Normally rats will spend more time exploring the novel object; old rats and rats that have impaired recognition memory spend equal amounts of time with both the familiar and novel object. When the rats are tested a second time, a different set of objects is used. Subjects that do not meet the criterion of 25 - $30 \mathrm{sec}$ exploration time are eliminated from the specific test in order to minimize the effects of different amounts of exploration time on subsequent performance.

\subsection{Statistics}

The initial analysis of the data involved a one-way ANOVA. Each particle/energy/time was analyzed independently. Comparisons between the different doses of radiation and the non-irradiated controls at each time point were performed using Fisher's Protected-T.

\section{Results}

The results are presented in Figures 1-6 and summarized in Figure 7. In general, the control animals in all experiments spent more time with the novel object than with the familiar object. For all particles tested, exposure to HZE particles and protons produced a disruption of recognition memory. An apparent exception was with the experiment exposing younger subjects to ${ }^{12} \mathrm{C}$ particles. However, only three of the ten non-irradiated controls met the criteria (25 - 30 sec exploration time) so that the results cannot be accepted as completely accurate.

For the most part, the dose that disrupted novel object recognition in the older animals was less than or equal to the dose needed to disrupt cognitive performance in younger animals (Figure 7). Recognition memory performance of the older animals was disrupted by a dose of HZE particles and protons that was $10 \%-50 \%$ of the dose needed to disrupt performance in the younger animals, regardless of the absolute value of the dose needed to disrupt recognition memory in the younger subjects. Exposure to a dose of HZE particles or protons that did not disrupt performance in younger subjects was sufficient to disrupt recognition memory in rats as they grew older. The enhanced effectiveness of a lower dose of HZE particle irradiation on the second test in older subjects did not result from prior experience with the specific task. If the prior experience affected subsequent performance, the performance of the control animals, as well as the irradiated subjects, should have been altered. Since there was no systematic change in the performance on the non-irradiated control animals, it is unlikely that the prior experience with the task affected subsequent performance.

The major exceptions to the observation that lower doses of HZE particles were needed to disrupt cognitive performance in the older subjects were in the animals exposed to the two energies of ${ }^{16} \mathrm{O}$ particles (600 and 1000 

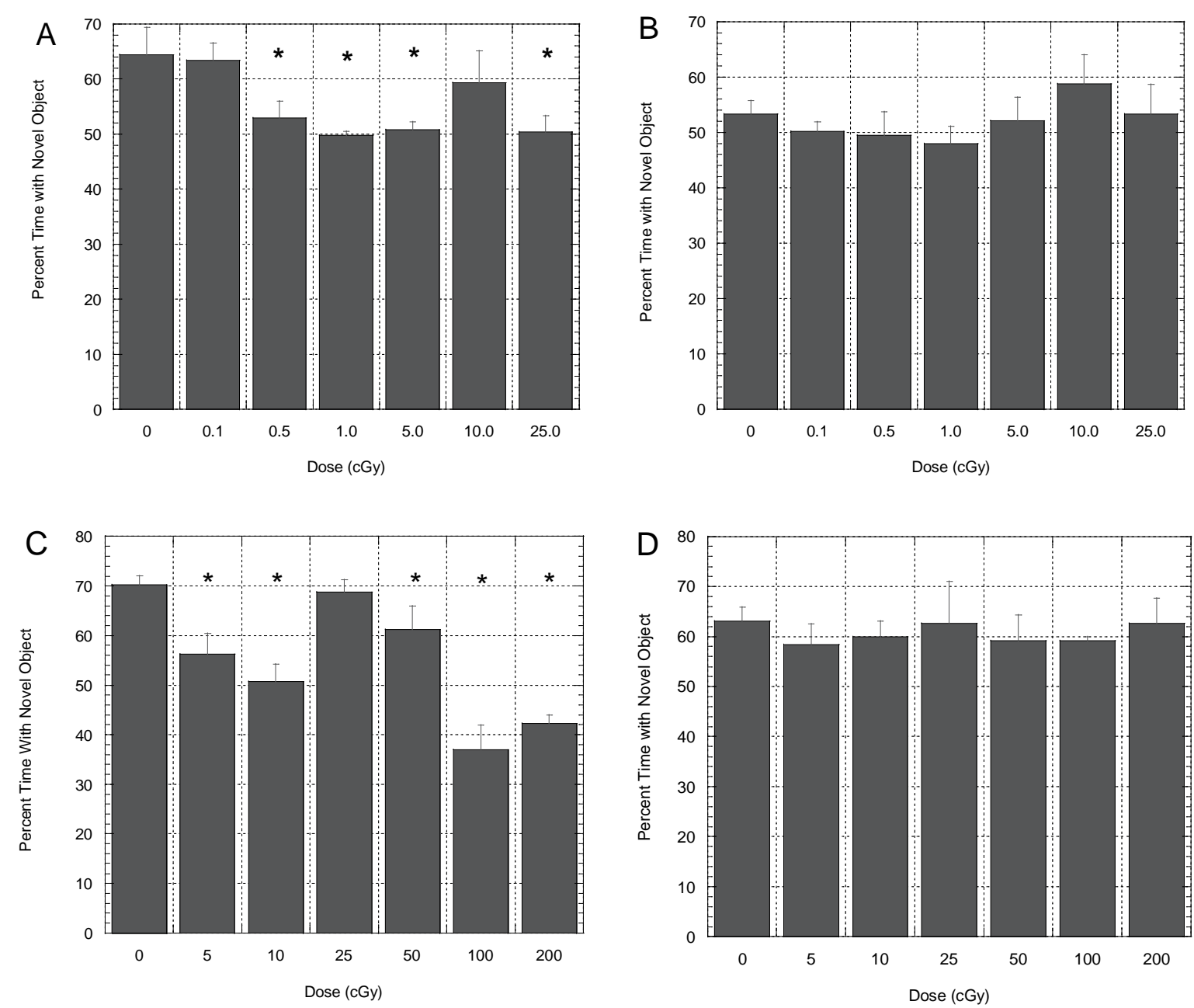

Figure 1. Effects of exposure to ${ }^{16} \mathrm{O}$ particles on novel object recognition performance measured as the percent time exploring the novel object. Mean \pm standard error of the mean (S.E.M.). ${ }^{*}$ Significantly different than non-irradiated (0 cGy) controls. (A) (B) $600 \mathrm{MeV} / \mathrm{n}$. (A) 2 months post-irradiation; (B) 10 months post-irradiation. (C) (D) $1000 \mathrm{MeV} / \mathrm{n}$. (C) 4 months post-irradiation; (D) 12 months post-irradiation.

$\mathrm{MeV} / \mathrm{n}$ ) and to ${ }^{28} \mathrm{Si}$ particles (600 and $1000 \mathrm{MeV} / \mathrm{n}$ ), although the reasons for this were different for the two particles. The performance of the younger animals exposed to the different doses of ${ }^{16} \mathrm{O}$ particles showed a significant reduction in object recognition memory compared to the non-irradiated controls (Figure 1). When retested 8 months following the first test the non-irradiated controls ( 0 cGy) showed a reduction in the percentage of time spent with the novel object, failing to show a significant preference for the novel object. As such, there was no difference between the rats exposed to ${ }^{16} \mathrm{O}$ particles and the non-irradiated controls.

With regard to the rats exposed to ${ }^{28} \mathrm{Si}$ particles, the effect of irradiation on cognitive function at two ages varied as a function of particle energy. Whereas the older rats exposed to $380 \mathrm{MeV} / \mathrm{n}^{28} \mathrm{Si}$ particles (Figure 3) showed a disruption of recognition memory at a lower dose than the older rats ( $0.50 \mathrm{cGy}$ compared to $10 \mathrm{cGy}$ ), the threshold for the rats exposed to $600 \mathrm{MeV} / \mathrm{n}^{28} \mathrm{Si}$ particles (Figure 3C, Figure 3D) did not vary as a function of age: the threshold for the disruption of novel object recognition performance was $10 \mathrm{cGy}$ at both times, which was the lowest dose tested. In contrast, the older rats exposed to $1000 \mathrm{MeV} / \mathrm{n}^{28} \mathrm{Si}$ particles required a higher dose to disrupt recognition memory compared to the younger subjects (50 cGy in the older animals compared to 25 cGy in the younger animals; Figure 3E, Figure 3F). However, as noted with the results following exposure to ${ }^{16} \mathrm{O}$ particles, the increase in the dose needed to disrupt recognition memory in the rats when retested nine months following the original test may have resulted from the reduction in the percentage of time the non-irradiated control rats spent exploring the novel object. 

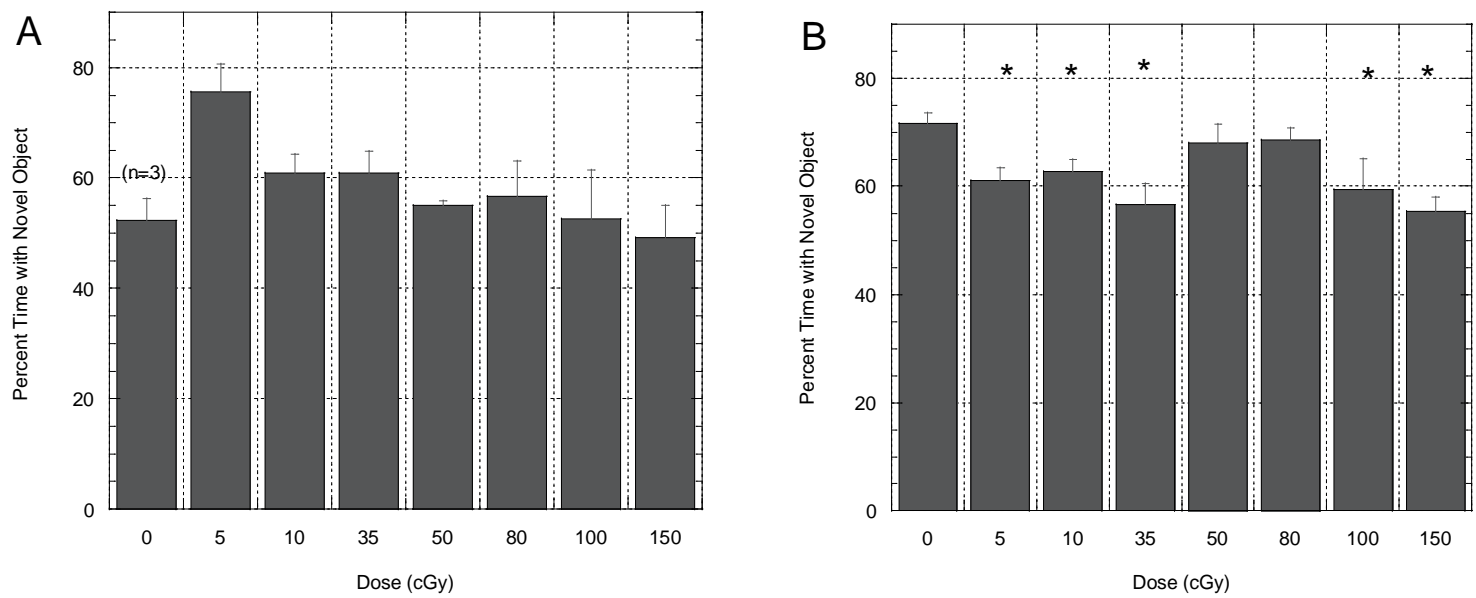

Figure 2. Effects of exposure to ${ }^{12} \mathrm{C}$ particles $(290 \mathrm{MeV} / \mathrm{n})$ on novel object recognition performance. Mean \pm S.E.M. *Significantly different than non-irradiated (0 cGy) controls. (A) 1 month post-irradiation; (B) 11 months post-irradiation. Because the measure of the performance of the younger control subjects was not reliable (only 3 non-irradiated controls met criterion on the first test), it was not possible to statistically compare the performance of the radiated and control subjects. Because the measure of the performance of the younger control subjects was not reliable (only 3 non-irradiated controls met criterion on the first test), it was not possible to statistically compare the performance of the radiated and control subjects.

The sensitivity of the subject to different particles and different energies of the same particle, measured as the lowest tested dose which disrupted performance ("threshold” dose), varied as a function of both the specific particle and particle LET. In general, the lower the LET of the HZE particle the lower the dose of HZE particles needed to disrupt cognitive performance at both time points. In contrast to the effects of exposure to HZE particles the dose of protons needed to disrupt novel object recognition performance was higher than that of any HZE particle despite its low LET.

\section{Discussion}

Exposure to NASA relevant doses [14] [15] of HZE particles and protons produces a disruption of recognition memory, such that irradiated rats, unlike the non-irradiated controls, fail to spend more time with a novel object, indicating that they are no longer able to remember the familiar object. The performance decrement is apparent starting one month following irradiation. The results of the present experiments are consistent with previous reports that exposure to NASA relevant doses of HZE particles and protons produce a decrement in cognitive performance 1 - 2 months following irradiation [6] [8]-[11] [13]. At both earlier and later time points exposure to HZE particles produced a disruption of object recognition memory, such that irradiated rats failed to distinguish between a novel and familiar object. Not only is there no recovery of recognition memory as a function of the passage of time following exposure; rather, the results of the present experiments indicate that older organisms are more sensitive to the effects of HZE particles and protons than are younger subjects. Exposure to doses of different HZE particles and protons that did not affect cognitive performance in younger subjects did affect cognitive performance in subjects when they were retested 8 - 10 months following the first test (9 - 17 months post irradiation).

These results are consistent with previously reported results [11] in which motivation to obtain reinforcement was measured using operant responding on fixed-ratio reinforcement schedule. With this measure of cognitive performance also there is an interaction between age and exposure to HZE particles such that as organisms age there is an increasing sensitivity to ${ }^{56} \mathrm{Fe}$ particles with lower doses disrupting performance. Similar results have been obtained when older rats (7 - 18 months of age) have been exposed ${ }^{56} \mathrm{Fe}$ particles. The doses needed to disrupt performance of older rats on operant responding (a measure of motivation to respond to changes in reinforcement contingencies [12]) and on plus-maze performance (a measure of baseline anxiety levels [16]) are significantly lower than the doses needed to disrupt the performance of younger rats. Also similar to previous results [11] is the observation (Figure 1) that once threshold is reached it is possible that a higher dose will not disrupt performance. The factor(s) that may influence this inconsistency in threshold determination is not 

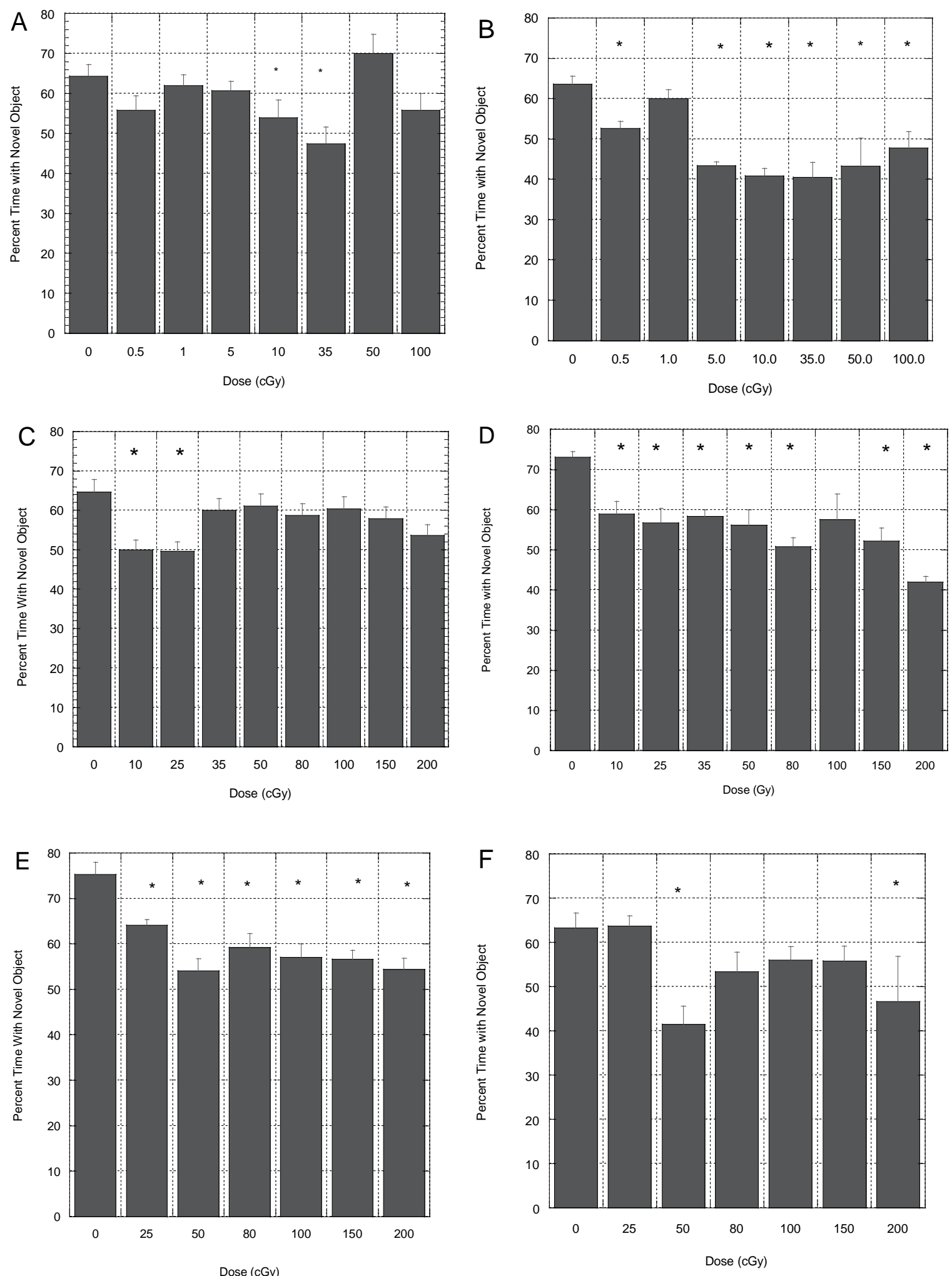

Figure 3. Effects of exposure to ${ }^{28}$ Si particles on novel object recognition performance. Mean \pm standard error of the mean (S.E.M.). *Significantly different than non-irradiated (0 cGy) controls. (A) (B) $380 \mathrm{MeV} / \mathrm{n}$. (A) 4 months post-irradiation; (B) 10 months post-irradiation. (C) (D) $600 \mathrm{MeV} / \mathrm{n}$. (C) 5 months-post irradiation; (D) 9 months post-irradiation; (E) (F)1000 MeV/n. (E) 4 months post-irradiation; (F) 13 months post-irradiation. 

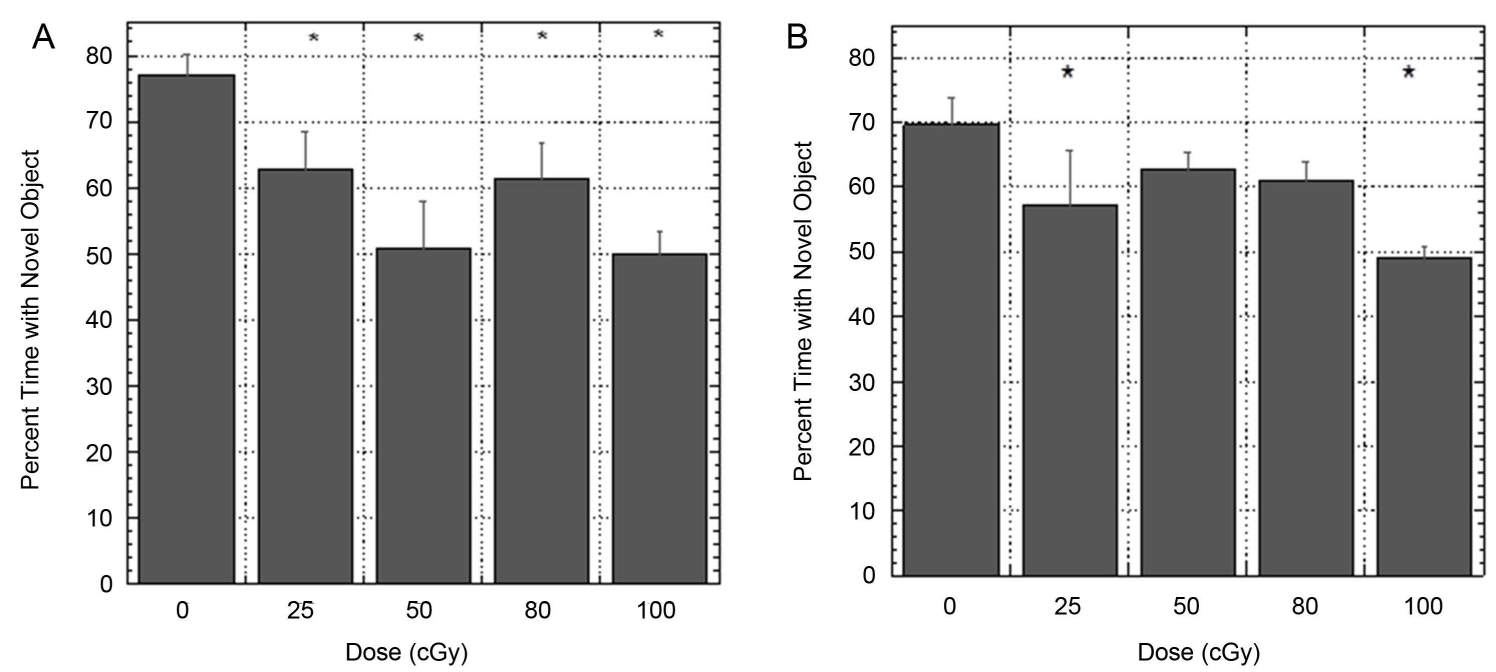

Figure 4. Effects of exposure to ${ }^{48} \mathrm{Ti}$ particles $(1100 \mathrm{MeV} / \mathrm{n})$ on novel object recognition performance. Mean \pm S.E.M. *Significantly different than non-irradiated (0 cGy) controls. (A) 7 months post-irradiation; (B) 17 months post-irradiation.
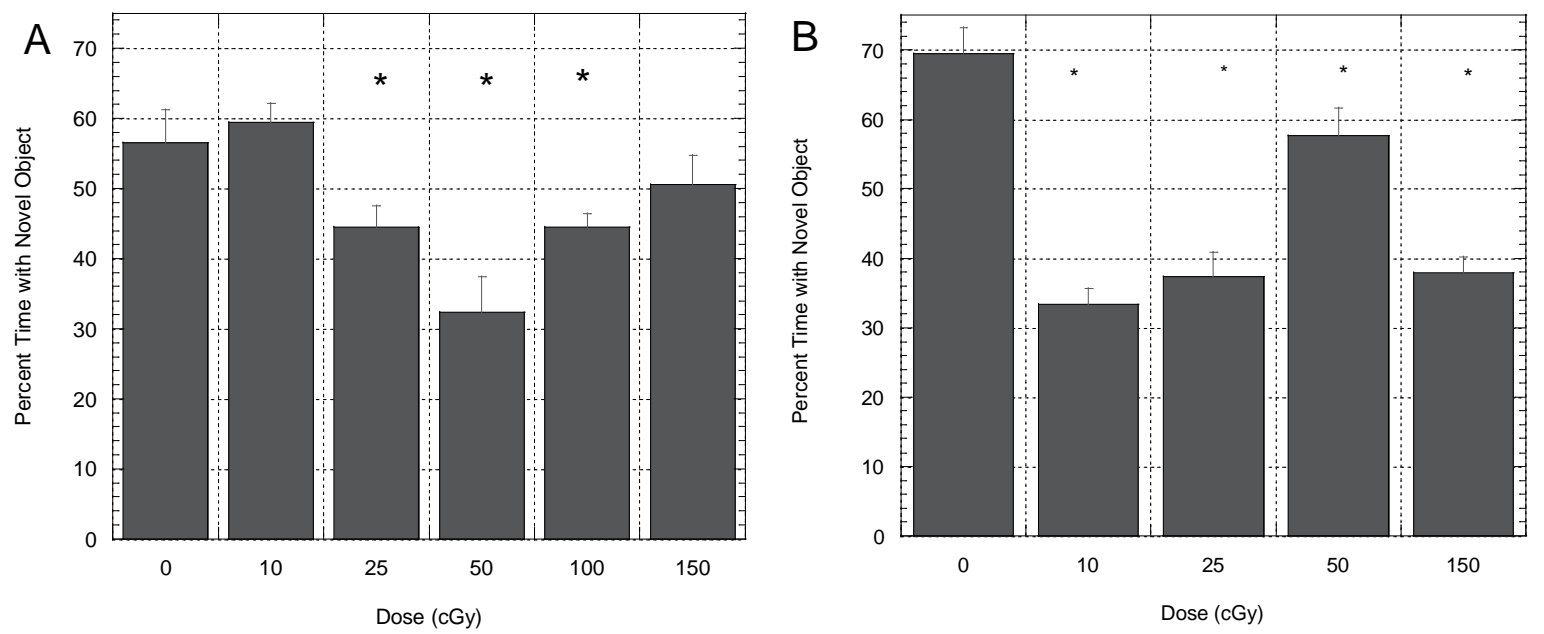

Figure 5. Effects of exposure to ${ }^{56} \mathrm{Fe}$ particles $(600 \mathrm{MeV} / \mathrm{n})$ on novel object recognition performance. Mean \pm S.E.M. *Significantly different than non-irradiated (0 cGy) controls. (A) 3 months post-irradiation; (B) 12 months post-irradiation. The animals exposed to $100 \mathrm{cGy}$ are not included in (B) because not enough subjects met criterion.

certain, but it is possible that this variability reflects the individual variability inherent in behavioral testing. Also similar to previous results [11] is the observation (Figure 1) that once threshold is reached it is possible that a higher dose will not disrupt performance. The factor(s) that may influence this inconsistency in threshold determination is not certain, but it is possible that this variability reflects the individual variability inherent in behavioral testing.

Although the general pattern of responding was such that exposure to lower doses of HZE particles and protons disrupted recognition memory in older subjects, this pattern was not observed with all particles tested. The older rats exposed to both energies of ${ }^{16} \mathrm{O}$ particles failed to show a lower threshold for the disruption of recognition memory than when they were first tested at a younger age. In this instance the failure to show an age-enhanced sensitivity to exposure to ${ }^{16} \mathrm{O}$ particles did not represent a recovery of function in the CNS because both the older and younger irradiated rats spent the same amount of time with the novel object. Rather, the failure to observe a significant decrease in novel object exploration in the older subjects exposed to ${ }^{16} \mathrm{O}$ particles reflects the fact that the older, non-irradiated controls did not spend more time with the novel object than the younger rats. The reason for the failure of the control animals to explore the novel object is not clear. While previous research has shown that older rats explore less than younger rats [17] [18], this cannot account for the present 

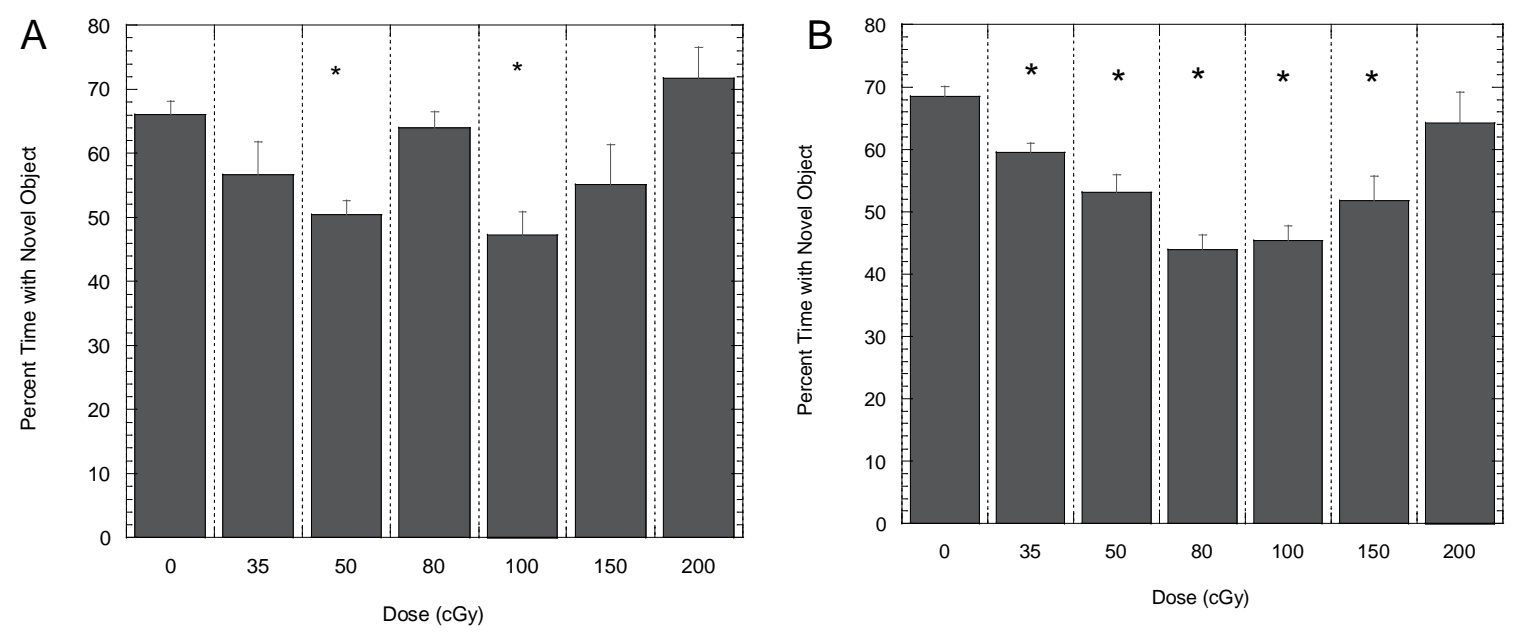

Figure 6. Effects of exposure to protons $(1000 \mathrm{MeV} / \mathrm{n})$ on novel object recognition performance. Mean \pm S.E.M. *Significantly different than non-irradiated (0 cGy) controls. (A) 4 months post-irradiation; (B) 13 months post-irradiation.

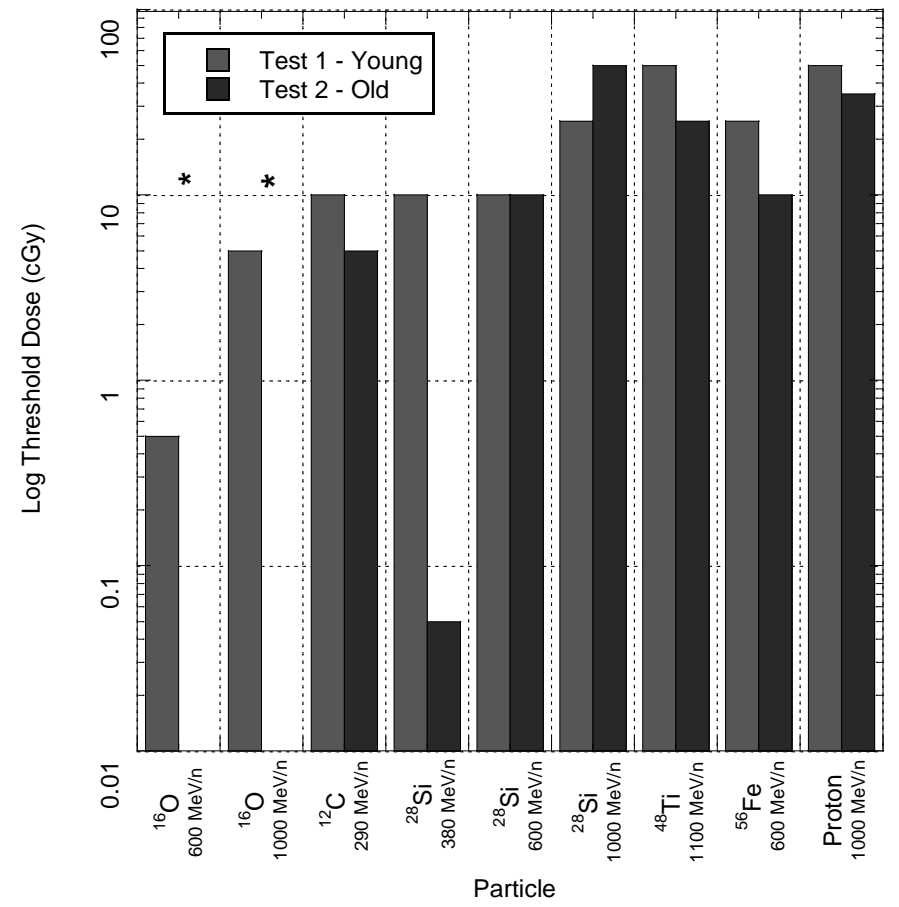

Figure 7. Summary of the effects of exposure to HZE particles and protons on the on the dose needed to disrupt object recognition performance on the first (young) and second test (old). The data is presented as log of threshold dose: the dose needed to produce a significant disruption of object recognition memory. ${ }^{*}$ There was no effect of irradiation on the performance of the older animals (Test 2) for either energy of ${ }^{16} \mathrm{O}$ particles.

effects because the controls for the other particles showed significant greater amount of exploration of the novel object than did the irradiated subjects.

Similarly, the failure to find a decrease in the HZE particle-induced threshold as a function of age following exposure to ${ }^{28} \mathrm{Si}$ particles may have resulted from two factors. First, with regard to the $600 \mathrm{MeV} / \mathrm{n}^{28} \mathrm{Si}$ particles, the 10 cGy dose which was the threshold dose in the young animals was the lowest dose tested. As a result, whether or not the threshold dose for the older animals would have been lower cannot be determined. Second, the increased threshold dose (50 cGy) for the older subjects exposed to $1000 \mathrm{MeV} / \mathrm{n}^{28} \mathrm{Si}$ may also reflect a decrease in exploration in the non-irradiated controls, as was observed with the older animals exposed to ${ }^{16} \mathrm{O}$ par- 
ticles. This interpretation would be consistent with the observation that for all other particles/energies there was a decrease in the threshold needed to produce a performance decrement when the subjects were re-tested 4 - 10 months following exposure.

It should be noted, however, that the concept of threshold in the present context is arbitrary for several reasons. First, to establish the absolute threshold below which there would be no disruption of responding requires repeated exposure of the same animal to a range of doses of a specific HZE particle; a procedure which cannot be utilized with radiation exposure. Second, for some particles, such as 600 and $1000 \mathrm{MeV} / \mathrm{n}^{28} \mathrm{Si}$ (Figures 3C-F), a low enough dose was not utilized which did not affect performance; so that the actual threshold would be lower than reported here. Nonetheless, the relative thresholds reported here are consistent for both the younger and older animals and can be considered to approximate the actual thresholds for disrupting recognition memory.

The present results are also consistent with the results of a previous study [19] which evaluated the relationship between particle energy/LET and its effectiveness in disrupting cognitive performance using operant responding on an ascending fixed-ratio reinforcement schedule (a measure of the motivation of an organism to respond for reinforcement). In those experiments it was noted that the effectiveness of different particles (e.g., ${ }^{16} \mathrm{O}$ and ${ }^{56} \mathrm{Fe}$ ) in disrupting the performance of young subjects varied as a function of particle LET, such that lower doses of ${ }^{16} \mathrm{O}$ or ${ }^{12} \mathrm{C}$ particles were needed to disrupt performance than was needed for ${ }^{56} \mathrm{Fe}$ particles. The present results show that this pattern of effectiveness was seen with the older subjects as well: the threshold doses needed to recognition memory was lower for the lower LET particles.

Exposure to HZE particles produces "accelerated" aging [4] [5], such that exposing young subjects to the types of radiation that encountered during exploratory class mission produces cognitive and motor deficits that are characteristic of the old organism. The similarities in the cognitive effects of exposure to HZE particle irradiation and aging may reflect the fact that the similar mechanisms mediate both natural and HZE particle-induced aging. Current theories of aging propose a role for oxidative stress [20]-[24] and neuroinflammation [25] [26] in the process. In turn, the cognitive deficits observed in aged organisms have been linked to the effects of oxidative stress and neuroinflammation on brain function [27]-[29]. Heavy particle radiation, like other toxic stimuli, produces oxidative stress [30]-[32] and neuroinflammation [32]-[34] resulting in changes in neuronal and cognitive function. In effect, exposure to HZE particles accelerates the aging process [4] [5] in terms of changes in both neuronal function and cognitive performance.

The present results, together with previous reports [11] [12], indicate that there is no recovery of cognitive function resulting from the passage of time. Rather, there is an interaction between the age of the organism and the effects of exposure to HZE particles on cognitive performance, such that exposure to doses of HZE particles or protons that may not produce an immediate effect on cognitive performance may produce an effect as the organism ages. These results suggest that the changes in neural function and behavior produced by irradiation are secondary to the changes occurring as a result of aging. As these results relate to exposure to cosmic rays on exploratory class missions, it is possible that astronauts, who are most likely to be middle-aged, will be more at risk for a performance deficit in cognitive functioning as the mission proceeds. Because there is no recovery of cognitive function with the passage of time, these results also suggest that the effects of exposure to the types of radiation encountered on exploratory class missions may affect the quality of life of astronauts following the conclusion of the mission.

\section{Acknowledgements}

We thank Michael Sivertz of the Collider-Accelerator Department at BNL for providing the detailed explanation of the dosimetry. The research reported here was carried out under NASA grants: NNJ06HD93G, NNX08AM66G, and NNX13AB73G.

\section{References}

[1] Cucinotta, F.A., Schimmerling, W., Saganti, P.B., Wilson, J.W., Peterson, L.E., Badhwar, G.D. and Dicello, J.F. (2001) Space Radiation Cancer Risks and Uncertainties for Mars Missions. Radiation Research, 156, 682-688. http://dx.doi.org/10.1667/0033-7587(2001)156[0682:SRCRAU]2.0.CO;2

[2] Edwards, A.A. (2001) RBE of Radiations in Space and the Implications for Space Travel. Physica Medica, 27, 147152. 
[3] Schimmerling, W., Cucinotta, F.A. and Wilson, J.A. (2003) Radiation Risk and Human Space Exploration. Advances in Space Research, 3, 27-34. http://dx.doi.org/10.1016/S0273-1177(02)00653-1

[4] Joseph, J.A., Hunt, W.A., Rabin, B.M. and Dalton, T.K. (1992) Possible “Accelerated Aging” Induced by ${ }^{56}$ Fe Heavy Particle Irradiation: Implications for Manned Space Flights. Radiation Research, 130, 88-93.

http://dx.doi.org/10.2307/3578484

[5] Joseph, J.A., Hunt, W.A., Rabin, B.M., Dalton, T.K. and Harris, A.H. (1993) Deficits in Striatal Muscarinic Receptor Sensitivity Induced by ${ }^{56} \mathrm{Fe}$ Heavy Particle Irradiation: Further “Age-Radiation” Parallels. Radiation Research, 135, 257-261. http://dx.doi.org/10.2307/3578303

[6] Shukitt-Hale, B., Casadesus, G., Carey, A., Rabin, B.M. and Joseph, J.A. (2007) Exposure to ${ }^{56}$ Fe Irradiation Accelerates Normal Brain Aging and Produces Deficits in Learning and Memory. Advances in Space Research, 39, 10871092. http://dx.doi.org/10.1016/j.asr.2006.11.005

[7] Rabin, B.M., Buhler, L.L., Joseph, J.A., Shukitt-Hale, B. and Jenkins, D.G. (2002) Effects of Exposure to ${ }^{56}$ Fe Particles or Protons on Fixed-ratio Operant Responding in Rats. Journal of Radiation Research, 43, S225-S228. http://dx.doi.org/10.1269/jrr.43.S225

[8] Villasana, L., Rosenberg, J. and Raber, J. (2010) Sex-Dependent Effects of ${ }^{56}$ Fe Irradiation on Contextual Fear Conditioning in C57BL/6J Mice. Hippocampus, 26, 19-23.

[9] Raber, J., Rosi, S., Chakraborti, A., Fishman, K., Dayger, C., et al. (2011) Effects of ${ }^{56}$ Fe-Particle Cranial Radiation on Hippocampus-Dependent Cognition Depend on the Salience of Environmental Stimuli. Radiation Research, 176, 521527. http://dx.doi.org/10.1667/RR2635.1

[10] Shukitt-Hale, B., Casadesus, G., McEwen, J.J., Rabin, B.M. and Joseph, J.A. (2000) Spatial Learning and Memory Deficits Induced by ${ }^{56}$ Fe Radiation Exposure. Radiation Research, 154, 28-33. http://dx.doi.org/10.1667/0033-7587(2000)154[0028:SLAMDI]2.0.CO;2

[11] Rabin, B.M., Joseph, J.A. and Shukitt-Hale, B. (2005) A Longitudinal Study of Operant Responding in Rats Irradiated when 2 Months Old. Radiation Research, 164, 552-555. http://dx.doi.org/10.1667/RR3349.1

[12] Rabin, B.M., Joseph, J.A., Shukitt-Hale, B. and Carrihill-Knoll, K.L. (2012) Interaction between Age of Irradiation and Age of Testing in the Disruption of Operant Performance Using a Ground-Based Model for Exposure to Cosmic Rays. AGE, 34, 121-131. http://dx.doi.org/10.1007/s11357-011-9226-4

[13] Rabin, B.M., Carrihill-Knoll, K.L., Hinchman, M., Shukitt-Hale, B., Joseph, J.A., et al. (2009) Effects of Heavy Particle Irradiation and Diet on Object Recognition Memory in Rats. Advances in Space Research, 43, 1193-1199. http://dx.doi.org/10.1016/j.asr.2009.01.015

[14] Curtis, S.B., Vazquez, M.E., Wilson, J.W., Atwell, W., Kim, M. and Capala, J. (1998) Cosmic Ray Hit Frequencies in Critical Sites in the Central Nervous System. Advances in Space Research, 22, 197-207. http://dx.doi.org/10.1016/S0273-1177(98)80011-2

[15] Zeitlin, C., Hassler, D.M., Cucinotta, F.A., et al. (2013) Measurements of Energetic Particle Radiation in Transit to Mars on the Mars Science Laboratory. Science, 340, 1080-1084. http://dx.doi.org/10.1126/science.1235989

[16] Rabin, B.M., Carrihill-Knoll, K.L., Carey, A.N., Shukitt-Hale, B., Joseph, J.A. and Foster, B.C. (2007) Elevated Plus-maze Performance of Fischer-344 Rats as a Function of Age and Exposure to ${ }^{56} \mathrm{Fe}$ Particles. Advances in Space Research, 39, 981-986. http://dx.doi.org/10.1016/j.asr.2006.11.013

[17] Malin, D.H., Lee, D.R., Goyarzu, P., Chang, Y.-H., Ennis, L.J., et al. (2011) Short-Term Blueberry-Enriched Diet Prevents and Reverses Object Recognition Memory Loss in Aging Rats. Nutrition, 27, 338-342. http://dx.doi.org/10.1016/j.nut.2010.05.001

[18] Weinstock, M., Bejar, C., Schorer-Apelbaum, D., Panarsky, R., Luques, L., et al. (2013) Dose-Dependent Effects of Ladostigil on Microglial Activation and Cognition in Aged Rats. Journal of Neuroimmune Pharmacology, 8, 345-355. http://dx.doi.org/10.1007/s11481-013-9433-0

[19] Rabin, B.M., Carrihill-Knoll, K.L. and Shukitt-Hale, B. (2011) Operant Responding Following Exposure to HZE Particles and its Relationship to Particle Energy and Linear Energy Transfer. Advances in Space Research, 48, 370-377. http://dx.doi.org/10.1016/j.asr.2011.03.008

[20] Lee, W.H., Sonntag, W.E., Mitschelen, M., Yan, H. and Lee, W.L. (2010) Irradiation Induces Regionally Specific Alterations in Pro-inflammatory Environments in Rat Brain. International Journal of Radiation Biology, 86, 132-144. http://dx.doi.org/10.3109/09553000903419346

[21] Barja, G. (2004) Free Radicals and Aging. Trends in Neuroscience, 27, 595-600. http://dx.doi.org/10.1016/j.tins.2004.07.005

[22] Bokov, A. Chaudhuri, A. and Richardson, A. (2004) The Role of Oxidative Damage and Stress in Aging. Mechanisms of Aging and Development, 125, 811-826. http://dx.doi.org/10.1016/j.mad.2004.07.009

[23] Floyd, R.A. and Hensley, K. (2002) Oxidative Stress in Brain Aging: Implications for Therapeutics of Neurodegenera- 
tive Diseases. Neurobiology of Aging, 23, 795-807. http://dx.doi.org/10.1016/S0197-4580(02)00019-2

[24] Ashok, A. and Ali, R. (1999) The Aging Paradox: Free Radical Theory of Aging. Experimental Gerontology, 34, 293303. http://dx.doi.org/10.1016/S0197-4580(02)00019-2

[25] Norden, D.M. and Godbout, J.A. (2013) Review: Microglia of the Aged Brain: Primed to Be Activated and Resistant to Regulation. Neuropathology and Applied Neurobiology, 39, 19-34. http://dx.doi.org/10.1111/j.1365-2990.2012.01306.x

[26] Pizza, V., Agresta, A., D’Acunto, C.W., Festa, M. and Capasso, A. (2011) Neuroinflamm-Aging and Neurodegenerative Diseases: An Overview. CNS \& Neurological Disorders Drug Targets, 10, 621-634. http://dx.doi.org/10.2174/187152711796235014

[27] Ownby, R.L. (2010) Neuroinflammation and Cognitive Aging. Current Psychiatry Reports, 12, 39-45. http://dx.doi.org/10.1007/s11920-009-0082-1

[28] Hein, A.M. and O’Banion, M.K. (2012) Neuroinflammation and Cognitive Dysfunction in Chronic Disease and Aging. Journal of Neuroimmune Pharmacology, 7, 3-62. http://dx.doi.org/10.1007/s11481-011-9340-1

[29] Chen, J., Buchanan, J.B., Sparkman, N.L., Godbout, J.P., Freund, G.G. and Johnson, R.W. (2008) Neuroinflammation and Disruption in Working Memory in Aged Mice after Acute Stimulation of the Peripheral Innate Immune System. Brain Behavior and Immunity, 22, 301-311. http://dx.doi.org/10.1016/j.bbi.2007.08.014

[30] Riley, P.A. (1994) Free Radicals in Biology: Oxidative Stress and the Effects of Ionizing Radiation. International Journal of Radiation Biology, 65, 27-33. http://dx.doi.org/10.1080/09553009414550041

[31] Denisova, N., Shukitt-Hale, B., Rabin, B.M. and Joseph, J.A. (2002) Brain Signaling and Behavioral Responses Induced by Exposure to ${ }^{56} \mathrm{Fe}$ Radiation. Radiation Research, 158, 725-734. http://dx.doi.org/10.1667/0033-7587(2002)158[0725:BSABRI]2.0.CO;2

[32] Poulose, S.M., Bielinski, D.F., Carrihill-Knoll, K.L, Rabin, B.M. and Shukitt-Hale, B. (2011) Exposure to Oxygen $\left({ }^{16}\right.$ O) Particle Irradiation Causes Age-Like Decrements in Rats Through Increased Oxidative Stress, Inflammation and Loss of Autophagy. Radiation Research, 176, 761-769. http://dx.doi.org/10.1667/RR2605.1

[33] Rola, R., Sarkissian, V., Obenaus, A., Nelson, G.A., Otsuka, S., et al. (2005) High-LET Radiation Induces Inflammation and Persistent Changes in Markers of Hippocampal Neurogenesis. Radiation Research, 164, 556-560. http://dx.doi.org/10.1667/RR3412.1

[34] Jenrow, K.A., Brown, S.L., Lapanowski, K., Naei, H., Kolozsvary, A. and Kin, J.H. (2012) Selective Inhibition of Microglia-Mediated Neuroinflammation Mitigates Radiation-Induced Cognitive Impairment. Radiation Research, 179, 549-556. http://dx.doi.org/10.1667/RR3026.1 
Scientific Research Publishing (SCIRP) is one of the largest Open Access journal publishers. It is currently publishing more than 200 open access, online, peer-reviewed journals covering a wide range of academic disciplines. SCIRP serves the worldwide academic communities and contributes to the progress and application of science with its publication.

Other selected journals from SCIRP are listed as below. Submit your manuscript to us via either submit@scirp.org or Online Submission Portal.
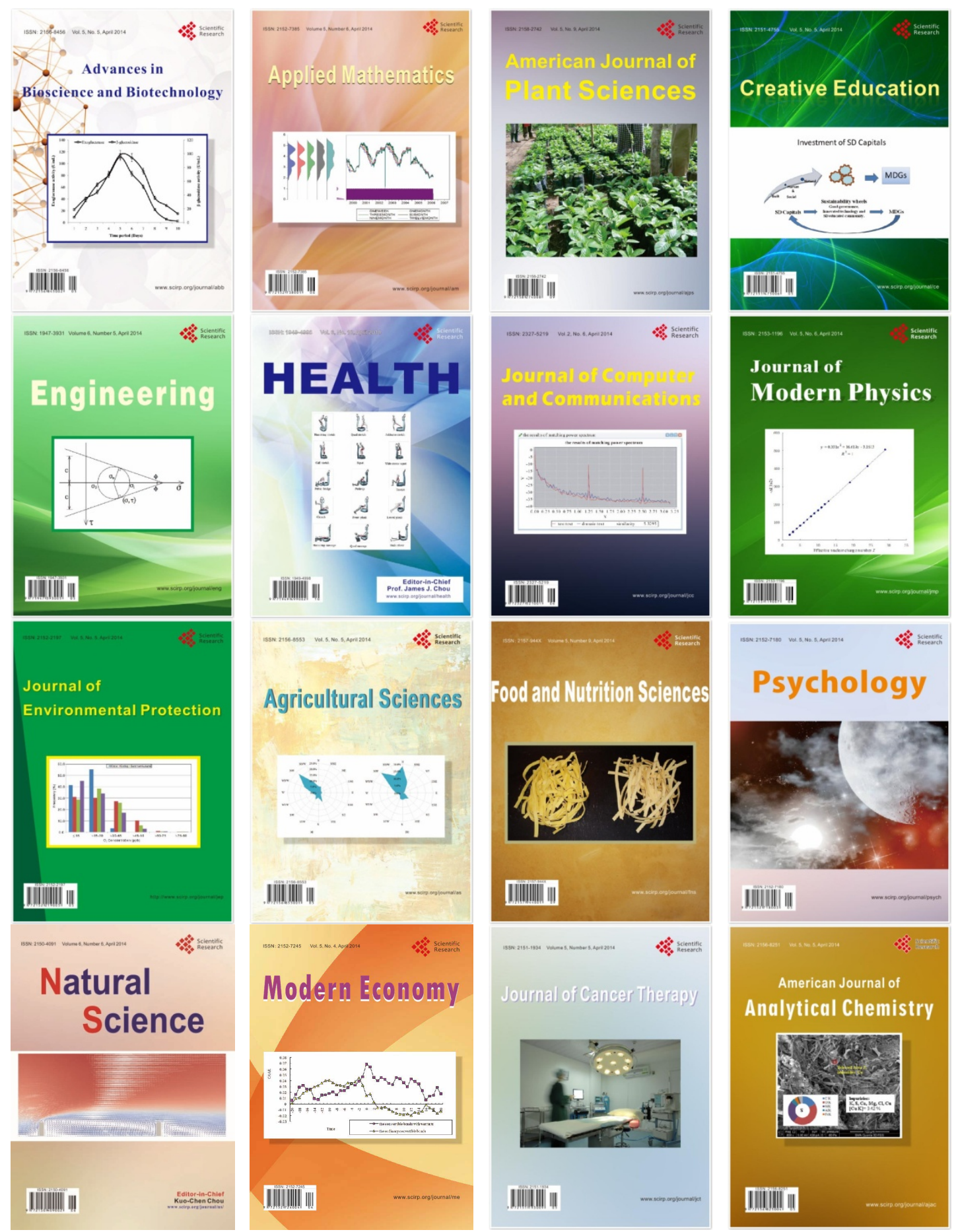